\title{
Från redaktionen
}

Umeå-redaktionen som haft ansvar för Socialvetenskaplig tidskrift sedan 2010 håller nu på att avsluta vår femårsperiod. Under nästa femårsperiod kommer redaktionen att ligga i Lund. Den nya redaktionen vid Socialhögskolan där introduceras för närvarande i arbetet och den tar över vid årsskiftet 2015. Nya manus ska redan nu skickas till redaktionen i Lund.

I detta nummer får vi ta del av många olika aspekter av det sociala arbetets innehåll, varav relationer är en central del. Det kan som i Bengt Svensson och Anette Skårners artikel "Sex och narkotika. Mäns erfarenheter under uppbrottsprocessen från ett drogmissbruk" handla om sexualitet. Det nya livet efter ett långvarigt drogmissbruk innebär stora förändringar, inte minst i förhållande till de nya relationer som ska inledas och fyllas med ett annat innehåll än under livet som missbrukare. Men själva behandlingen som de genomgått är enligt författarna ensidigt fixerad vid att beroendet till själva drogen ska upphöra. Resten får de klara själva. Det kan bli svårt att etablera nya sexuella relationer utan verktyg i form av nya "sexuella script", metaforen som används för att tydliggöra normsystemet och dess olika former. Med sådan kunskap blir det möjligt att föreställa sig hur man socialt ska handskas med sin sexualitet. Artikeln ställer nya frågor om det sociala arbetet med missbrukare där sexualitetens roll i relationer ställs i fokus.

I artikeln "Anhörigomsorg mot betalning: Biståndshandläggare om sent-i-livet-invandrares önskemål" av Emilia Forssell, Sandra Torres och Anna Olaison beskrivs hur problematisk relationen till klienter kan te sig $\mathrm{i}$ biståndshandläggarnas vardag och vi får möta de våndor som de brottas med då de ska besluta om en rimlig hjälpinsats. Är rättvisa att alla ska få samma insats vid samma diagnos? Eller är det att insatsen ska prövas mot individuella önskemål och det som förefaller logiskt utifrån dessa? Ska familjens omsorgsinsatser stödjas ekonomiskt? Hur går det då med jämställdheten i den yngre generationen med kvinnors yrkesarbete och framtida pension? Hur mycket ska samhället bry sig om den generationens rätt till autonomi gentemot samhälle och familj? Här sätts invanda föreställningar och värderingar på prov, medan samhället blir allt mer mångfaldigt och ett universellt normsystem om hur vi ska förhålla oss till varandra därmed blir allt svårare att upprätthålla.

Vad som är verksamt i en insats kan vara svårt att veta, inte minst när dessa gäller unga personer vars liv fortfarande är formbart. Sofia Enell presenterar i artikeln "Banor i samhällsvården - en tvåårsstudie om unga som utretts på SiS-institution" ungas väg genom och ut ur samhällsvården. Som en bland flera metoder samlades data in genom intervjuer med unga och deras socialsekreterare under en tvåårsperiod. Det gick att urskilja åtminstone fyra typer av banor, som utmärktes av mer eller mindre dialog och eget inflytande för klienten, av mer eller mindre frivillighet respektive tvång, och av mer eller mindre inblandning av andra aktörer. Det är viktigt att förstå hur interaktion och personliga förutsättningar påverkar vägen ut ur samhällsvård. Därmed är vi inne på numrets andra tema -yrkeskunskapen. 
Adekvat kunskap är viktig att ha när beslut som berör enskilda personer ska fattas. Det kan tyckas självklart och ingen skulle argumentera emot ett sådant påstående. Men expertkunskap hänger inte alltid med i politiska förändringar. Arbetsförmåga är ett aktuellt, svårhanterligt och politiserat begrepp som har både medicinska och legala aspekter. Definitionen är dock otydlig skriver Lena Eriksson, Moten Sager Carin Staland-Nyman och Gunnel Hensing i artikeln "Expertis, sjukskrivning och mötet mellan normal och post-normal vetenskap". Beslutsstödet riktar sig till en läkarprofession som inte har en fullvärdig kompetens för att göra adekvata bedömningar. Multiprofessionella team kan vara en lösning. Vetenskapsteoretiskt får detta konsekvenser och författarna talar om "post-normal kunskap", en breddad expertkunskap som är kontextdriven och inbegriper ett flertal perspektiv, och där begrepp som "tyst kunskap"kan få en renässans.

Sjukhuskuratorns yrke är väletablerat men med en diffus expertkunskap. Kuratorn arbetar i en miljö där många andra yrkesgrupper ingår, vilket skapar behov av att upprätta gränser mot andra kunskapsområden utan att skapa konflikter. Yrkeskunskapen ska vare sig bli utslätad eller alltför specifik. Gunilla Framme diskuterar i artikeln "Vad gör socionomerna för skillnad i den psykiatriska vården?" de dilemman som kan uppstå i förhållande till patienter, till såväl andra yrkesgrupper som andra socionomer. Begrepp som "helhetssyn", "psykosocialt arbetssätt", alla med ett brett tillämpningsområde och med relationer på olika plan i fokus. Något förbryllande är varför kuratorernas förankring $\mathrm{i}$ socionomyrket är så svag.

Mer utrymme borde ges för professionen att utveckla sin kunskap kan man tycka. Men människobehandlande organisationer med sina interna prioriteringar, förhoppningsvis grundade i expertkunskap, löper risk att bli ogenomträngliga för en allmänhet vars liv ofta berörs av deras beslut. I artikeln "Institutionella villkor för mediehantering - en jämförande kartläggning mellan socialtjänst, skola och polis" - skriven av Jesper Enbom, Stefan Sjöström ${ }^{1}$ och Adam Öhman - problematiseras spänningen mellan allmänhetens intresse av insyn och myndighetens intresse av att framstå som välfungerande. Styrning, insyn och omvärldsintresse blir viktiga begrepp i analysen. Variationerna är stora mellan och inom de olika typerna av organisationer. Här sticker framför allt polisen ut i jämförelse med de kommunala förvaltningarna med en långt mer utvecklad mediehantering, sannolikt framtvingad av att verksamheten har ett större nyhetsvärde.

Kan ett närmare förhållande mellan forskning och praktik leda till ett bättre praktiskt socialt arbete respektive en bättre forskning? Dimitris Michailakis och Verner Schirmer tar upp en för alla som arbetar inom området socialt arbete viktig diskussion, den om vad som händer när det sociala arbetets teori och praktik integreras. Det finns emellertid en eller flera latenta konflikter mellan teorin och praktiken. Ska forskningen styras av praktikens behov av kunskapsutveckling eller ska forskningen stå fri från dessa intressen? Kan forskningen bidra till kunskapsutveckling eller är möjligheten till kunskapsöverföring

1 Manuskriptet har enligt redaktions jävs-policy genomgått en utvidgad lektörsgranskning då en av författarna ingår i redaktionen. 
endast en illusion? Författarna rådbråkar de olika perspektiven och vi hoppas att deras artikel ska få en fortsättning i en engagerad och initierad diskussion.

$\mathrm{Nu}$ till något helt annat. Socialvetenskaplig tidskrift delar sedan 2011 ut ett pris till Axel Anderssons minne för bästa vetenskapliga originalartikel publicerad under året. Prissumman är $15000 \mathrm{kr}$, varav hälften går till en av pristagaren vald organisation som arbetar med frågor som stärker social rättvisa. Därutöver får pristagaren/na "road-movie" med Axel Andersson som på 1960-talet besöker de platser han bodde på som barn, samt ett diplom.

Axel Andersson levde mellan åren 1886 och 1974 och var med om en omfattande samhällsförändring. Han såldes på auktion i Vena, Kalmar län, tretton gånger runt förra sekelskiftet. Hans liv är väldokumenterat såväl i böcker som i film. Han kan sägas personifiera välfärdsstatens framväxt och den värderingsförskjutning som skett, och för vilken forskningen spelat en viktig roll.

Axel Andersson-priset för åren 2012 och 2013 delades ut i samband med det Nordiska FORSA symposium i Malmö 8-10 oktober. Vinnarna av 2012 års pris blev Verner Denvall och Kerstin Johansson för artikeln "Kejsarens nya kläder - implementering av evidensbaserad praktik i socialt arbete". Prismotiveringen lyder:

Artikeln är ett viktigt och lite annorlunda inlägg i den pågående debatten om evidensbaserat socialt arbete (EBP). Författarna visar bland annat att statens försök att implementera EBP fixerats vid formerna för genomförandet av denna nya styrning av det lokala sociala arbetet, medan frågorna om hur den nödvändiga kunskapen skall utvecklas och hur det praktiska arbetet skall förändras, liksom de brukare som skulle gynnas av nyordningen, hamnat i skymundan. Artikeln är välskriven, argumenterande och analytisk. Den är väl förankrad i teori och forskning och har hög relevans för såväl forskning som praktik.

Vinnare av 2013 års pris blev Anna Johansson för artikeln "Låt dem aldrig slå ner dig. Bloggen som arena för patientaktivism". Prismotiveringen lyder:

Denna originella artikel är ett bidrag till forskningen om maktförhållanden mellan brukare och rådgivare. Genom att använda en ny social arena och uttrycksform - bloggen visar hon hur gamla maktmönster reproduceras men delvis omskapas. Med en driven stilistik gestaltar Anna Johansson nyanser i nya former av kritik mot psykiatrin och hur detta blir möligt genom ett nytt medium.

Med priset uppmärksammas värdet av att ett utbyte sker på svenska mellan experter inom och utanför akademin. Genom att lyfta fram en person, Axel Andersson, vill vi också visa att personliga livsöden speglar en samhällsstruktur som går att påverka och där socialvetenskaplig forskning är en viktig aktör.

Stina Johansson, Stefan Sjöström, Katarina Andersson 